\title{
Surgery of Cystic Tumors of the Pancreas - Why, When, and How?
}

\author{
Jan G. D'Haese Jens Werner \\ Department of General, Visceral, and Transplantation Surgery, Ludwig Maximilians-University, Munich, Germany
}

\author{
Keywords \\ Intraductal papillary mucinous neoplasm, IPMN . \\ Mucinous cystic neoplasm, MCN . \\ Solid pseudopapillary neoplasm, SPN . \\ Serous cystic neoplasm, SCN - Morbidity
}

\section{Summary}

The management of cystic pancreatic neoplasms has increasingly gained clinical attention due to their frequent incidental detection by cross-sectional imaging and their potential for progression to pancreatic cancer. Surgical resection is warranted for all mucinous cystic neoplasms, solid pseudopapillary neoplasms, and main-duct intraductal papillary mucinous neoplasms since these lesions harbor a major risk for malignant transformation. For branch-duct IPMN (BD-IPMN), the risk for malignancy is considerably lower so that some lesions may be safely followed while others require surgical resection. The clinical challenge lies in making the correct preoperative diagnosis and estimation of the risk of malignancy in BD-IPMN. Therefore, the existing evidence and current guidelines on the management of cystic lesions of the pancreas are summarized and controversially discussed from a surgical point of view.

(C) 2018 S. Karger GmbH, Freiburg

\section{Introduction}

Until the late 1980s, cystic tumors of the pancreas were thought to be rare neoplasms. Over the past decades, however, we have learned from autopsy studies and surgical series that cystic tumors occur much more often than anticipated $[1,2]$. Among these cystic tumors of the pancreas, intraductal mucinous neoplasms of the pancreas (IPMN) are probably the most common entity. Nowa- days, up to $20 \%$ of all pancreatic resections are attributed to cystic tumors of the pancreas in high-volume surgical centers [3-5]. The most important reason for this increasing incidence is the widespread use of modern abdominal imaging technologies since in the majority of cases, cystic pancreatic tumors are incidentally found on cross-sectional imaging for other abdominal complaints. With increasing incidence, cystic tumors of the pancreas have become a challenging problem in clinical practice. It is well established that especially mucinous cystic tumors (most commonly IPMN and mucinous cystic neoplasms (MCN)) harbor a significant risk for malignant transformation over time while other, mostly serous cystic lesions like serous cystic neoplasms (SCN) are generally benign. Today, the assessment of the individual patient's risk for malignancy and therefore judging the indication for surgery (versus observation) is the most challenging and relevant clinical task.

\section{Indications for Surgery - Why?}

Surgery for cystic tumors of the pancreas may be indicated for the control of clinical symptoms, for resection of benign or semimalignant lesions before malignant transformation, or for resection of malignant lesions before they metastasize. Out of these indications, suspected premalignant cystic lesions of the pancreas are the most frequent reason for surgical resection. Here, the treatment strategy aims at timely recognizing and resecting premalignant lesions before malignant transformation since the prognosis is poor once they have become malignant, similar to 'conventional' pancreatic ductal adenocarcinoma. In contrast, it is evident that not all cystic lesions harbor a risk of malignancy and therefore not all lesions require surgery. Great efforts are made to characterize these cystic lesions of the pancreas preoperatively. Characterization is usually based on clinical presentation and radiological findings, and sometimes on histology/cytology. Symptomatic cysts are as such suspicious and should undergo further investigation and treatment. Asymptomatic cysts, however, do not always require

\section{KARGER}

() 2018 S. Karger GmbH, Freiburg

Fax +497614520714
Prof. Dr. med. Jens Werner

Klinik für Allgemein-, Viszeral-, Gefäß- und Transplantationschirurgie

LMU Klinikum der Stadt München

Marchioninistraße 15, 81377 München, Germany

jens.werner@med.lmu.de 
Table 1. Overview of the current guidelines for the management of cystic tumors of the pancreas

\begin{tabular}{|c|c|c|}
\hline Guideline & Absolute indications for surgery & Relative indications for surgery \\
\hline $\begin{array}{l}\text { International Associ- } \\
\text { ation of Pancrea- } \\
\text { tology, 'Sendai } \\
\text { Criteria' [8] }\end{array}$ & $\begin{array}{l}\text { - 'high-risk stigmata' } \\
\text { - obstructive jaundice } \\
\text { - enhancing mural nodule }>5 \mathrm{~mm} \\
\text { - main pancreatic duct }>10 \mathrm{~mm}\end{array}$ & $\begin{array}{l}\text { - 'worrisome features' } \\
\text { - cyst }>3 \mathrm{~cm} \\
\text { - enhancing mural nodule }<5 \mathrm{~mm} \\
\text { - thickened/enhancing cyst walls } \\
\text { - main duct size } 5-9 \mathrm{~mm} \\
\text { - abrupt change in caliber of pancreatic } \\
\text { duct with distal pancreatic atrophy } \\
\text { - lymphadenopathy } \\
\text { - increased serum level of CA } 19-9 \\
\text { - cyst growth rate }>5 \mathrm{~mm} / 2 \text { years }\end{array}$ \\
\hline $\begin{array}{l}\text { European Study } \\
\text { Group on Cystic } \\
\text { Tumours of the } \\
\text { Pancreas [17] }\end{array}$ & $\begin{array}{l}\text { - cyst } \geq 4 \mathrm{~cm} \\
\text { - symptoms related to the pancreas } \\
\text { (e.g. jaundice, diabetes, acute } \\
\text { pancreatitis) } \\
\text { - mural nodules } \\
\text { - dilation of the main pancreatic } \\
\text { duct }>6 \mathrm{~mm} \text { diameter }\end{array}$ & $\begin{array}{l}\text { - rapidly increasing size } \\
\text { - elevated serum levels of CA 19-9 }\end{array}$ \\
\hline $\begin{array}{l}\text { American Gastroen- } \\
\text { terological Associa- } \\
\text { tion [19] }\end{array}$ & $\begin{array}{l}\text { - solid component and dilatation } \\
\text { of the main pancreatic duct } \\
>5 \mathrm{~mm} \text { on MRI and EUS } \\
\text { - cytology positive for malignancy }\end{array}$ & \\
\hline
\end{tabular}

treatment. For radiological characterization, magnetic resonance imaging and magnetic resonance cholangiopancreatography are the most applicable investigations, allowing the best classification of cystic lesions of the pancreas. This is described in detail in other articles of this special focus of Visceral Medicine. Despite all efforts, it is still impossible to accurately differentiate benign from potentially malignant cysts preoperatively [6-8].

\section{Observation versus Operation - When?}

Many different cystic lesions of the pancreas have been described and classified. However, more than $90 \%$ of these cystic lesions are represented by one of the four most common cystic neoplasms, namely SCN, MCN, solid pseudopapillary neoplasms (SPN), and IPMN, which may be further divided into IPMN arising from the branch ducts of the pancreatic duct (BD-IPMN), those arising from the main pancreatic duct (MD-IPMN), and those which are a mixture of both (mixed-type IPMN). Out of these four types, SCN are the only cystic lesions that may always be safely observed. All other lesions potentially bear a risk of malignancy. For MCN, SPN, and MD-IPMN, the risk of malignant transformation is high; thus, surgical resection is generally indicated. BD-IPMN is the cystic tumor type that is most difficult to assess. While some BD-IPMN carry a major risk of malignant transformation, others are largely benign.

Management guidelines for the treatment of cystic lesions of the pancreas have fundamentally changed over the past two decades. Initially and until the 1990s, surgery was recommended for all mucinous neoplasms of the pancreas since they were thought to have a serious malignant potential $[9,10]$. Over time, it became evident that in a significant number of patients who underwent surgery for IPMN only low-grade dysplasia was found upon histological examination. With increasing evidence, an interdisciplinary group of renowned experts in their field gathered in Sendai, Japan, to review and summarize the existing data as the first international consensus guideline for the treatment of IPMN und MCN, which was published in 2006 [11]. Since then these so-called 'Sendai guidelines' have been updated, revised, and published in cooperation with the International Association of Pancreatology (IAP) as 'Fukuoka guidelines' in 2012 [6]. The latest update with only minor modifications was published in late 2017 (table 1) [8]. To date, these guidelines are widely accepted and reflect the current thinking of experts on the management of mucinous cystic neoplasms of the pancreas. These Sendai criteria were also the first to distinguish and classify the nowadays commonly used three subtypes of IPMN: MD-IPMN, BD-IPMN, and mixed-type IPMN. According to the 2017 Fukuoka guidelines, segmental or diffuse dilation of the main pancreatic duct of $>5 \mathrm{~mm}$ without other causes of obstruction defines MD-IPMN, while pancreatic cysts $>5 \mathrm{~mm}$ in size demonstrating communication with the main pancreatic duct but without main pancreatic duct dilation are classified as BD-IPMN, and lesions meeting criteria for both MD- and BD-IPMN are classified as mixed-type IPMN. Furthermore, this guideline defines so-called 'high-risk stigmata' and 'worrisome features' in an attempt to estimate the risk of malignancy (table 1). In a large meta-analysis, the 2006 Sendai guidelines have been shown to have a pooled sensitivity of $56 \%$ and specificity of $74 \%$ while the updated 2012 Fukuoka guidelines showed a much better pooled sensitivity of $83 \%$ but worse specificity of only $53 \%$ for the detection of high-grade dysplasia or invasive cancer [12]. Several aspects have been suggested to improve the sensitivity and specificity of the current guideline. A 
Table 2. Overview of the management concepts for cystic lesions of the pancreas at the Ludwig MaximiliansUniversity, Munich, Germany

\begin{tabular}{lll}
\hline Diagnosis (suspected) & Dignity & Concept \\
\hline SCN & benign & observation, resection when symptomatic or $>4 \mathrm{~cm}$ \\
\hline MCN & high risk of malignancy & resection \\
\hline SPN & high risk of malignancy & resection \\
\hline IPMN & & \\
Main-duct IPMN & high risk of malignancy & resection \\
Mixed-type IPMN & high risk of malignancy & resection \\
Branch-duct IPMN & risk of malignancy & selection: \\
& & $>2 \mathrm{~cm}$ : resection \\
& $<2 \mathrm{~cm}+$ Fukuoka-positive: resection \\
& & $1-2 \mathrm{~cm}+$ Fukuoka-negative: individual judgement/limited resection \\
& $<1 \mathrm{~cm}$ : observation
\end{tabular}

SCN = Serous cystic neoplasm; $\mathrm{MCN}=$ mucinous cystic neoplasm; SPN = solid pseudopapillary neoplasm; IPMN = intraductal papillary mucinous neoplasm. recent study of a high-volume pancreatic center showed a high rate of malignancy of $59 \%$ in patients with a main pancreatic duct size of 5-9 $\mathrm{mm}$ so that the authors suggest that a main pancreatic duct size of $\geq 5 \mathrm{~mm}$ should be regarded as a 'high-risk stigmata' instead of a 'worrisome feature' and that patients should undergo surgery [13]. Furthermore, diabetes mellitus in IPMN patients has recently been found to be associated with high-grade dysplasia as well as invasive cancer and may therefore be regarded as an additional worrisome feature [14]. Other factors that have been discovered to be associated with malignancy but have not (yet) found their way into the current guidelines are pain symptoms, weight loss, and elevated serum carcinoembryonic antigen $[15,16]$.

Over time, two additional guidelines for the management of cystic tumors of the pancreas were developed and published. In 2013, Del Chiaro et al. [17] published the 'European expert consensus statement on cystic tumors of the pancreas' on behalf of the European Study Group on Cystic Tumors of the Pancreas which has increasingly gained attention in Europe (table 1). An updated version of theses European guidelines has been presented at the United European Gastroenterology Week 2017 in Barcelona and is now reported on by Scholten et al. [18] in this issue. At last, the American Gastroenterology Association (AGA) published a gastroenterological guideline in 2015, which suggests a much more conservative approach with restricted indications for surgery compared to the other two guidelines [19] (table 1). However, increasing evidence suggests that even the previous guidelines may miss a significant amount of malignant tumors and high-grade dysplasia [20]. Therefore, on the one hand, it does not seem surprising that it could be shown that with these very conservative AGA guidelines fewer patients receive unnecessary surgery while, on the other hand, an unacceptable high number of malignant tumors and high-grade dysplasia are missed [21]. Consequently, these AGA guidelines have not found their way into routine clinical practice. All three current management guidelines are summarized in table 1 , whereas the current management concept at our institution is summarized in table 2.

The Fukuoka guidelines suggest surgery for 'young and fit' patients in some circumstances, which leaves a lot of room for inter- pretation [8]. It would make an interesting study to compare what gastroenterologists and surgeons would consider as 'young and fit' in this setting. With a steadily increasing mean life expectancy in Germany of currently 78.2 years for male and 83.0 years for female newborn inhabitants, patients as old as 60 or 65 years may be considered as 'young' [22]. Looking at life expectancy, it is especially interesting to notice the age-adjusted life expectancy which may be a lot higher than one would suspect. A 70- and an 80-year-old woman in Germany have a mean life expectancy of 16.8 and of 9.3 years, respectively, which is a long time span to follow up when it comes to the decision whether a cystic lesion of the pancreas should be observed (or resected) [22]. Furthermore, life expectancy has been shown to strongly depend on socio-economic status $( \pm 10$ years in Germany [23]) and has a great variability in between geographic regions and different countries. Besides age, comorbidities are an important consideration when deciding in which patients to recommend surgical resection. The risk of non-IPMN-related death increases with the presence and severity of comorbidities and has to be balanced against the potential risk of IPMN-associated malignancy and death. Elderly patients unfit for surgery may undergo observation since even in IPMN with worrisome features the 5 -year disease-specific survival may be as high as $96 \%$ in these patients [24]. However, presence of high-risk stigmata is associated with a $40 \%$ risk of IPMN-related death, which underlines the importance of surgery in surgically fit patients [24]. Patients with a high comorbidity burden and a Charlson Comorbidity Index (CACI) of $\geq 7$ have been shown to have a higher risk of non-IPMNrelated death, even in case of invasive IPMN-related cancer. Therefore, neither active surveillance nor surgical resection is justified in this selected subgroup [25].

\section{Surgical Resection - How?}

There is wide consensus among most clinicians that all MDIPMN, mixed-type IPMN, MCN, and SPN should be treated as potentially malignant lesions regardless of location and size. There- 
fore, surgical resection is advised in all patients fit for surgery. The surgical aim in these potentially malignant lesions is to perform an oncological resection with the respective lymphadenectomy to achieve negative surgical margins [5]. The most frequently performed standard oncological resections are therefore pancreaticoduodenectomies (Whipple procedure) or distal pancreatectomies and, in case of a cystic pathology in the entire gland or positive resection margins (high-grade dysplasia or invasive cancer), even total pancreatectomies. Patients with surgically resected noninvasive benign IPMN have excellent outcomes, with 10-year disease-specific survival rates of $>95 \%$ for both MD- and BD-IPMN [26]. Even patients with resected invasive cancer show 5- and 10year overall survival rates of around 50 and 35\%, respectively, which is much higher than those for non-IPMN-associated, 'conventional' pancreatic ductal adenocarcinoma $[27,28]$. This difference is probably due to the early diagnosis of invasive cancer in case of cystic pancreatic tumors rather than different biological behaviors since more advanced IPMN-associated (tubular/ductal) cancers and all patients with lymph node involvement show an identical poor long-term outcome as 'conventional' ductal adenocarcinoma [27, 29]. However, in case of IPMN-associated invasive cancer, the outcome also depends on the histological subtype. While colloid carcinomas, mostly arising from intestinal-type MDIPMN, show the highest 5 -year survival rates of about $61 \%$, tubular-type (ductal) cancers, mostly arising from gastric-type BDIPMN, show a poor 5-year survival of only $37 \%$ [28].

In order to evaluate resection margins and to make the intraoperative decision whether extended resection is warranted, intraoperative frozen section is indispensable in surgery for cystic tumors of the pancreas. The differentiation between benign IPMN, highgrade dysplasia, and even invasive carcinoma on frozen section may be difficult; the investigation should thus be performed by an experienced pancreatic pathologist. There is an ongoing debate on the management of those patients with positive margins for benign IPMN with low-grade dysplasia. In our center, resection margins with benign IPMN including low-grade dysplasia are left without additional surgery whereas IPMN with high-grade dysplasia are treated with extended resections. In patients where positive resection margins for high-grade dysplasia are found intraoperatively, we suggest extending the resection. However, there remains the problem of simultaneous lesions at different locations of the pancreas in MD-IPMN. In those cases, a negative resection margin does not represent the true situation. Thus, in some cases a total pancreatectomy remains the treatment of choice, especially in patients with a good long-term prognosis.

Nowadays, limited, non-anatomic resections are increasingly considered for some selected cases of BD-IPMN. These local resections include segmental resections and enucleations and may be performed laparoscopically in selected cases, depending on the location of the cystic lesion and especially the distance to the main pancreatic duct [5]. The advantage of parenchyma-sparing approaches is the preservation of exocrine and endocrine pancreatic function. Enucleations and segmental resections aim at limited R0 resections of benign cystic lesions without safety margins or lym- phadenectomy. Limited pancreatic resections are feasible and safe but show higher rates of postoperative pancreatic fistula which, however, do not translate to an increased perioperative mortality, which is almost zero in these cases [30-32]. Enucleations may prevent patients from typical complications of major pancreatic resections such as endocrine or exocrine insufficiencies. Therefore, limited resections of small Sendai/Fukuoka-negative BD-IPMN may be a good alternative to standard oncological procedures until reliable preoperative markers are available to distinguish between benign and premalignant or malignant lesions.

The morbidity and mortality associated with pancreatic resection has substantially decreased in the last decades. Mortality rates after surgical resections in large and experienced pancreatic centers have dropped below $2 \%$. However, it is important to recognize that the reported morbidity and mortality rates are based on oncological resections for ductal adenocarcinoma and not on resections for benign or premalignant lesions. Resection of these lesions is technically less challenging and leads to even lower morbidity and practically no mortality. From the patient's perspective, it has been shown that patients who underwent surgery for cystic lesions of the pancreas are highly satisfied with their decision to have surgery regardless of their final diagnosis or clinical outcome [33]. For patients with cystic lesions of the pancreas, fear of cancer is the main driver in the decision making process, and the anxiety of harboring a cyst is a greater cause of distress than postsurgical lifestyle changes [33].

Due to high recurrence rates and similar to conventional pancreatic ductal adenocarcinoma, a structured follow-up is recommended after surgery for all resected cystic lesions with high-grade dysplasia or invasive carcinoma [8]. The risk of recurrence of noninvasive IPMN is much lower when compared to invasive IPMN and is estimated around 5-9\% [34]. The recurrence of non-invasive lesions is almost always non-invasive and occurs after a median of more than 4 years after resection [35]. Therefore, and because of the elevated risk of concomitant pancreatic ductal adenocarcinoma, continuing surveillance of surgically fit patients is also suggested after resection of non-invasive lesions. Furthermore, the risk of malignancy in surveillance of non-invasive IPMN may last for 10 years or more, which strongly supports continued surveillance even after 5 years of follow-up [36]. Only cysts that remain smaller than $1.5 \mathrm{~cm}$ for more than 5 years may be considered as low-risk for progression to cancer [36].

\section{Conclusion}

Cystic lesions of the pancreas, especially all mucinous cysts, have to be considered as precursors to invasive pancreatic cancer unless proven otherwise (e.g. SCN). Surgical resection is the treatment of choice for all MCN, SPN, as well as MD-IPMN and mixedtype IPMN. Resection of these premalignant lesions offers a unique opportunity to avoid the development of pancreatic cancer and, subsequently, to improve the otherwise poor prognosis. For BDIPMN, most experts recommend resection if these are $>3 \mathrm{~cm}$ in 
size and/or symptomatic or if suspicious 'high-risk stigmata' like nodules, thickened cystic wall, increased serum CA 19-9, lymphadenopathy, or cyst growth are present. Limited resections including enucleations should be considered as an alternative to conservative treatment in small Fukuoka-negative lesions in surgically fit patients. Patients should undergo postoperative radiological observation due to the relevant risk of recurrence and development of metachronous lesions in the pancreatic remnant after resection. After surgical resection of cystic lesions of the pancreas, patients show an excellent overall survival with an unrestricted quality of life.

\section{Disclosure Statement}

The authors declare that they have not conflicts of interest.

\section{References}

1 Kimura W, Nagai H, Kuroda A, Muto T, Esaki Y: Analysis of small cystic lesions of the pancreas. Int J Pancreatol 1995; 18:197-206.

2 Kosmahl M, Pauser U, Peters K, Sipos B, Lüttges J, Kremer B, Klöppel G: Cystic neoplasms of the pancreas and tumor-like lesions with cystic features: a review of 418 cases and a classification proposal. Virchows Arch 2004;445:168-178.

3 Wada K, Kozarek RA, Traverso LW: Outcomes following resection of invasive and noninvasive intraductal papillary mucinous neoplasms of the pancreas. Am J Surg 2005; 189:632-636; discussion 637.

4 Spinelli KS, Fromwiller TE, Daniel RA, Kiely JM, Nakeeb A, Komorowski RA, Wilson SD, Pitt HA: Cystic pancreatic neoplasms: observe or operate. Ann Surg 2004;239:651-657; discussion 657-659.

5 Werner J, Fritz S, Büchler MW: Intraductal papillary mucinous neoplasms of the pancreas - a surgical disease. Nat Rev Gastroenterol Hepatol 2012;9:253-259.

-6 Tanaka M, Fernandez-del Castillo C, Adsay V, Chari S, Falconi M, Jang JY, Kimura W, Levy P, Pitman MB, Schmidt CM, Shimizu M, Wolfgang CL, Yamaguchi K, Yamao K: International consensus guidelines 2012 for the management of IPMN and MCN of the pancreas. Pancreatology 2012;12:183-197.

7 Brugge WR, Lewandrowski K, Lee-Lewandrowski E, Centeno BA, Szydlo T, Regan S, Fernandez-del Castillo C, Warshaw AL: Diagnosis of pancreatic cystic neoplasms: a report of the cooperative pancreatic cyst study. Gastroenterology 2004;126:1330-1336.

8 Tanaka M, Fernandez-Del Castillo C, Kamisawa T, Jang JY, Levy P, Ohtsuka T, Salvia R, Shimizu Y, Tada M, Wolfgang CL: Revisions of international consensus Fukuoka guidelines for the management of IPMN of the pancreas. Pancreatology 2017;17:738-753.

$\checkmark$ Warshaw AL, Compton CC, Lewandrowski K, Cardenosa G, Mueller PR: Cystic tumors of the pancreas. New clinical, radiologic, and pathologic observations in 67 patients. Ann Surg 1990;212:432-443; discussion 444-445.

10 Thompson LD, Becker RC, Przygodzki RM, Adair CF, Heffess CS: Mucinous cystic neoplasm (mucinous cystadenocarcinoma of low-grade malignant potential) of the pancreas: a clinicopathologic study of 130 cases. Am J Surg Pathol 1999;23:1-16.

11 Tanaka M, Chari S, Adsay V, Fernandez-del Castillo C Falconi M, Shimizu M, Yamaguchi K, Yamao K, Matsuno S: International consensus guidelines for management of intraductal papillary mucinous neoplasms and mucinous cystic neoplasms of the pancreas. Pancreatology 2006;6:17-32.

12 Heckler M, Michalski CW, Schaefle S, Kaiser J, Büchler MW, Hackert T: The Sendai and Fukuoka consensus criteria for the management of branch duct IPMN - a meta-analysis on their accuracy. Pancreatology 2017; 17:255-262.

13 Hackert T, Fritz S, Klauss M, Bergmann F, Hinz U, Strobel O, Schneider L, Büchler MW: Main-duct intraductal papillary mucinous neoplasm: high cancer risk in duct diameter of 5 to $9 \mathrm{~mm}$. Ann Surg 2015;262: 875-880; discussion 880-881.
14 Morales-Oyarvide V, Mino-Kenudson M, Ferrone CR, Sahani DV, Pergolini I, Negreros-Osuna AA, Warshaw AL, Lillemoe KD, Fernandez-Del Castillo C: Diabetes mellitus in intraductal papillary mucinous neoplasm of the pancreas is associated with high-grade dysplasia and invasive carcinoma. Pancreatology 2017;17:920-926.

15 Attiyeh MA, Fernandez-Del Castillo C, Al Efishat M, et al: Development and validation of a multi-institutional preoperative nomogram for predicting grade of dysplasia in intraductal papillary mucinous neoplasms (IPMNs) of the pancreas: a report from the Pancreatic Surgery Consortium. Ann Surg 2018;267:157-163.

16 Jang JY, Park T, Lee S, et al: Proposed nomogram predicting the individual risk of malignancy in the patients with branch duct type intraductal papillary mucinous neoplasms of the pancreas. Ann Surg 2017;266: 1062-1068.

17 Del Chiaro M, Verbeke C, Salvia R, Klöppel G, Werner J, McKay C, Friess H, Manfredi R, Van Cutsem E, Lohr M, Segersvard R: European experts consensus statement on cystic tumours of the pancreas. Dig Liver Dis 2013;45:703-711.

18 Scholten 1, van Huijgevoort NCM, van Hooft JE, Besselink MG, Del Chiaro M: Pancreatic cystic neoplasms: different types, different management, new guidelines. Visc Med 2018;34:DOI: 10.1159/000489641.

19 Vege SS, Ziring B, Jain R, Moayyedi P: American Gastroenterological Association institute guideline on the diagnosis and management of asymptomatic neoplastic pancreatic cysts. Gastroenterology 2015;148:819-822; quiz e12-13.

20 Fritz S, Klauss M, Bergmann F, Hackert T, Hartwig W, Strobel O, Bundy BD, Büchler MW, Werner J: Small (Sendai negative) branch-duct IPMNs: not harmless. Ann Surg 2012;256:313-320.

21 Lekkerkerker SJ, Besselink MG, Busch OR, Verheij J, Engelbrecht MR, Rauws EA, Fockens P, van Hooft JE: Comparing 3 guidelines on the management of surgically removed pancreatic cysts with regard to pathological outcome. Gastrointest Endosc 2017;85:10251031.

22 Statistisches Bundesamt/Federal Statistical Office: Ergebnisse aus der laufenden Berechnung von Periodensterbetafeln für Deutschland und die Bundesländer. 2016. www.destatis.de.

23 Lampert T, Kroll LE, Dunkelberg A: Soziale Ungleichheit der Lebenserwartung in Deutschland. Aus Politik und Zeitgeschichte (APUZ) 2007;42. www.bpb.de/ apuz/30179/soziale-ungleichheit-der-lebenserwartung-indeutschland? $p=$ all.

24 Crippa S, Bassi C, Salvia R, Malleo G, Marchegiani G, Rebours V, Levy P, Partelli S, Suleiman SL, Banks PA, Ahmed N, Chari ST, Fernandez-Del Castillo C, Falconi M: Low progression of intraductal papillary mucinous neoplasms with worrisome features and high-risk stig mata undergoing non-operative management: a midterm follow-up analysis. Gut 2017;66:495-506.

25 Sahora K, Ferrone CR, Brugge WR, Morales-Oyarvide V, Warshaw AL, Lillemoe KD, Fernandez-del Castillo C: Effects of comorbidities on outcomes of patients with intraductal papillary mucinous neoplasms. Clin Gastroenterol Hepatol 2015;13:1816-1823.
26 Crippa S, Fernandez-Del Castillo C, Salvia R, Finkelstein D, Bassi C, Dominguez I, Muzikansky A, Thayer SP, Falconi M, Mino-Kenudson M, Capelli P, Lauwers GY, Partelli S, Pederzoli P, Warshaw AL: Mucin-producing neoplasms of the pancreas: an analysis of distinguishing clinical and epidemiologic characteristics. Clin Gastroenterol Hepatol 2010;8:213-219.

27 Poultsides GA, Reddy S, Cameron JL, Hruban RH, Pawlik TM, Ahuja N, Jain A, Edil BH, IacobuzioDonahue CA, Schulick RD, Wolfgang CL: Histopathologic basis for the favorable survival after resection of intraductal papillary mucinous neoplasm-associated invasive adenocarcinoma of the pancreas. Ann Surg 2010;251:470-476.

28 Mino-Kenudson M, Fernandez-del Castillo C, Baba Y, Valsangkar NP, Liss AS, Hsu M, Correa-Gallego C, Ingkakul T, Perez Johnston R, Turner BG, Androutsopoulos V, Deshpande V, McGrath D, Sahani DV, Brugge WR, Ogino S, Pitman MB, Warshaw AL, Thayer SP: Prognosis of invasive intraductal papillary mucinous neoplasm depends on histological and precursor epithelial subtypes. Gut 2011;60:1712-1720.

29 Fernandez-del Castillo C, Adsay NV: Intraductal papillary mucinous neoplasms of the pancreas. Gastroen terology 2010;139:708-713, 713.e1-2.

30 Hackert T, Hinz U, Fritz S, Strobel O, Schneider L, Hartwig W, Büchler MW, Werner J: Enucleation in pancreatic surgery: indications, technique, and outcome compared to standard pancreatic resections. Langenbecks Arch Surg 2011;396:1197-1203.

31 Kaiser J, Fritz S, Klauss M, Bergmann F, Hinz U, Strobel O, Schneider L, Büchler MW, Hackert T: Enucleation: a treatment alternative for branch duct intraductal papillary mucinous neoplasms. Surgery 2017; 161:602-610.

32 Huttner FJ, Koessler-Ebs J, Hackert T, Ulrich A, Büchler MW, Diener MK: Meta-analysis of surgical outcome after enucleation versus standard resection for pancreatic neoplasms. Br J Surg 2015;102:10261036

33 Puri PM, Watkins AA, Kent TS, Maggino L, Jeganathan JG, Callery MP, Drebin JA, Vollmer CM: Decision-making for the management of cystic lesions of the pancreas: how satisfied are patients with surgery? J Gastrointest Surg 2018;22:88-97.

34 Kang MJ, Jang JY, Lee KB, Chang YR, Kwon W, Kim SW: Long-term prospective cohort study of patients undergoing pancreatectomy for intraductal papillary mucinous neoplasm of the pancreas: implications for postoperative surveillance. Ann Surg 2014;260:356363.

35 Morales-Oyarvide V, Fong ZV, Fernandez-Del Castillo C, Warshaw AL: Intraductal papillary mucinous neoplasms of the pancreas: strategic considerations. Visc Med 2017;33:466-476.

36 Pergolini I, Sahora K, Ferrone CR, Morales-Oyarvide V, Wolpin BM, Mucci LA, Brugge WR, Mino-Kenudson M, Patino M, Sahani DV, Warshaw AL, Lillemoe KD, Fernandez-Del Castillo C: Long-term risk of pancreatic malignancy in patients with branch duct intraductal papillary mucinous neoplasm in a referral center. Gastroenterology 2017;153:1284-1294.e1. 